\title{
Feedback inhibition of cellulolytic enzymes during saccharification of cellulosic biomass in order to enhance the productivity
}

\author{
Mariam Razzaq ${ }^{1}$, Shahzad Akbar Khan ${ }^{2 *}$, Zulfiqar Ahmed Abbasi ${ }^{3}$ and \\ Tanveer Ahmed ${ }^{3}$ \\ 1. Department of Biotechnology, University of Veterinary \& Animal Sciences, Lahore-Pakistan \\ 2. Department of Pathobiology, Faculty of Veterinary \& Animal Sciences, The University of Poonch, Rawalakot- \\ Pakistan \\ 3. Faculty of Veterinary \& Animal Sciences, The University of Poonch, Rawalakot-Pakistan \\ *Corresponding author's email: shahzadakbar@upr.edu.pk \\ Citation \\ Mariam Razzaq, Shahzad Akbar Khan, Zulfiqar Ahmed Abbasi and Tanveer Ahmed. Feedback inhibition of \\ cellulolytic enzymes during saccharification of cellulosic biomass in order to enhance the productivity. Pure and \\ Applied Biology. Vol. 7, Issue 3, pp1052-1063. http://dx.doi.org/10.19045/bspab.2018.700124
}

\begin{tabular}{llll}
\hline \hline Received: 19/04/2018 & Revised: 25/07/2018 & Accepted: 28/07/2018 & Online First: 03/08/2018 \\
\hline
\end{tabular}

\section{Abstract}

Current study revealed inhibitory effect of released end products on the activity of cellulolytic enzymes, both natural and synthetic substrates were compared comparatively.Genetically modified Escherichia coli containing the genes of Thermotogapetrophila for the production of endoglucanse, exoglucanse and $\beta$-glucosidase were provided for this research work production of bioenergy from plant biomas. These clones were named as $\mathrm{N}_{1}, \mathrm{X}_{3}$ and $\mathrm{G}_{1}$. These cultures were maintained by streaking these on ampicillin containing LB agar plates and were stored by placing them in cold cabinet at $4^{\circ} \mathrm{C}$. Sub culturing. It was demonstrated that accumulation of the end products upto a certain concentration with respect to the specific enzyme loading ( $\mathrm{U} / \mathrm{mL})$, led to the inactivation of the enzymes in saccharification mixture. Overall percentage saccharification of natural and synthetic substrate due to feedback inhibition of sequentially added cellulolytic enzymes was found $23.6 \%$ and $29.4 \%$ respectively. Variable concentrations of cellulolytic enzymes were added sequentially in order to overcome the inhibitory effect of the released end products during saccharification. This resulted in a significant increase in percentage saccharification of both natural and synthetic substrate upto 33.6\% and 34.5\% respectively.

Keywords: Biomass; $\beta$-glucosidase; cellulolytic enzymes; Saccharification

Introduction

Inevitable depletion of fossil fuels and its effect on global economics and environment has accelerated the research on alternative fuels. Over the last century energy consumption has increased undeviatingly. Bioethanol production from plant biomass is one way to decrease both utilization of fossil fuels and environmental pollution. It can be obtained from several cellulose based raw materials such as wheat straw, sugarcane bagasse, oat and barley straw by the process known as saccharification [1]. Saccharification of the 
lignocellulosic biomass can be carried out chemically as well as enzymatically. Highly specific cellulolytic enzymes are used for enzymatic hydrolysis of cellulose and hemicellulose present in the lignocellulosic raw materials into soluble monomeric sugars [2]. The concentration of the sugars in hydrolysates depends on the pretreatment and hydrolysis conditions of the substrate [3]. End products released exert inhibitory effects on cellulolytic enzymesupto different extent. Glucose is considered as a major inhibitor, directly inhibiting $\beta$-glucosidase activity. $B$ glucosidase inhibition results in increased cellobiose concentration in the medium that act as a strong inhibitor of enzymes with cellobiohydrolase activity termed as feedback inhibition [4].

Inhibition related problems during saccharification can be eliminated by taking several alternative measures. A little quantitative information is available about the end product inhibition of cellulolytic enzymes despite of intensive efforts. Usually the measurement of cellulose hydrolysis rate depends on the presence and absence of $\beta$ glucosidase. Experimental setup of continuous elimination of end products has been used in some studies [5].

Strategies to overcome feedback inhibition includes, use of high concentration of enzymes for saccharification, addition of extra $\beta$-glucosidases and continuous removal of sugars by ultrafilteration during enzymatic hydrolysis. Moreover to minimize the feedback inhibition due to the accumulation of cellobiosesaccharification system can be supplemented by the additional amount of exoglucanases in order to enhance the activity of these enzymes $[6,7]$.

Present study has focused to investigate the feedback inhibition of cellulolytic enzymes during saccharification of cellulosic biomass in order to enhance the productivity of the whole process.

\section{Materials and methods}

Genetically modified Escherichia coli containing the genes of Thermoto gapetrophila for the production of endoglucanse, exoglucanse and $\beta$ glucosidase were provided for this research work from the principal investigator of the project "Production of bioenergy from plant biomass". These clones were named as $\mathrm{N}_{1}$, $\mathrm{X}_{3}$ and $\mathrm{G}_{1}$. These cultures were maintained by streaking these on ampicillin containing LB agar plates and were stored by placing them in cold cabinet (Model: MPR1410,SANYO,Japan) at $4^{\circ}$ C. Sub culturing was done on regular basis after 15 days.LB agar medium was prepared according to method adopted by Bertani [8].

A loopful of single colony of cloned bacteria was transferred into sterilized Luria Bertani (LB) medium. Ampicillin was added in such manner that its final concentration became $0.1 \mathrm{mg}$ in the media. Culture was incubated at $37^{\circ} \mathrm{C}$ for $16-18$ hours. Seed culture was used as inoculum. $1 \%$ of the seed culture was inoculated into sterilized LB medium. Ampicillin was added in a concentration of $0.1 \mathrm{mg} / \mathrm{mL}$ in the media. After inoculation, media was incubated at $37^{\circ} \mathrm{C}$.

After 2 hours of incubation, absorbance of the inoculated media was checked at $600 \mathrm{~nm}$ for regular intervals. When absorbance of the media reached 0.6-0.8, IPTG (Isopropyl $\beta$-D1-thiogalactopyranoside) was added in a concentration of $0.5 \mathrm{mM}$. Media was incubated at $37^{\circ} \mathrm{C}$ for the time required for enzyme production. After required time of incubation, broth was centrifuged at 6000 rpm for 15 minutes. Supernatant used if the required enzyme was produced extracellularly. In case of intracellular enzyme, pellet was used for further processing. Pellet was suspended by weight in the specified volume of tris-cl buffer of $\mathrm{pH}$ 7.0. Sonication of the suspended material was done for the extraction of the intracellular enzyme. After sonication material was again 
centrifuged at $8000 \mathrm{rpm}$ for 10 minutes. Supernatant was collected which contained intracellular enzyme.

Pretreated wheat sample was used as substrate for cellulolytic enzymes as method describedbyElliston and Collins [9].Ceric Ammonium nitrate Assay was carried out by the method described byPanditaand Passey[10].

\section{Results and discussion}

Feedback inhibition of Endoglucanse $\mathrm{N}_{1}$ on synthetic substrate CMC (Carboxy methyl cellulose)

Variable endoglucanase unit's ranges from (50-200 U/mL) were added on synthetic substrate CMC (Carboxy methyl cellulose) during saccharification with respect to the different time intervals. Initially, $50 \mathrm{U} / \mathrm{mL}$ of endoglucanase were added. Distinctive decline in \% saccharification due to feedback inhibition was observed after 1 hour of incubation, when \% saccharification decreased from $14.68 \%$ to $10.67 \%$. Addition of more enzyme units $(100 \mathrm{U} / \mathrm{mL})$ at this point increased the $\%$ saccharification from $10.67 \%$ to $24.9 \%$. After this \% saccharification decreased, in spite of addition of more enzyme units ranges from $(150-200 \mathrm{U} / \mathrm{mL})$ upto fourth hours of incubation as shown in (Figure 1).

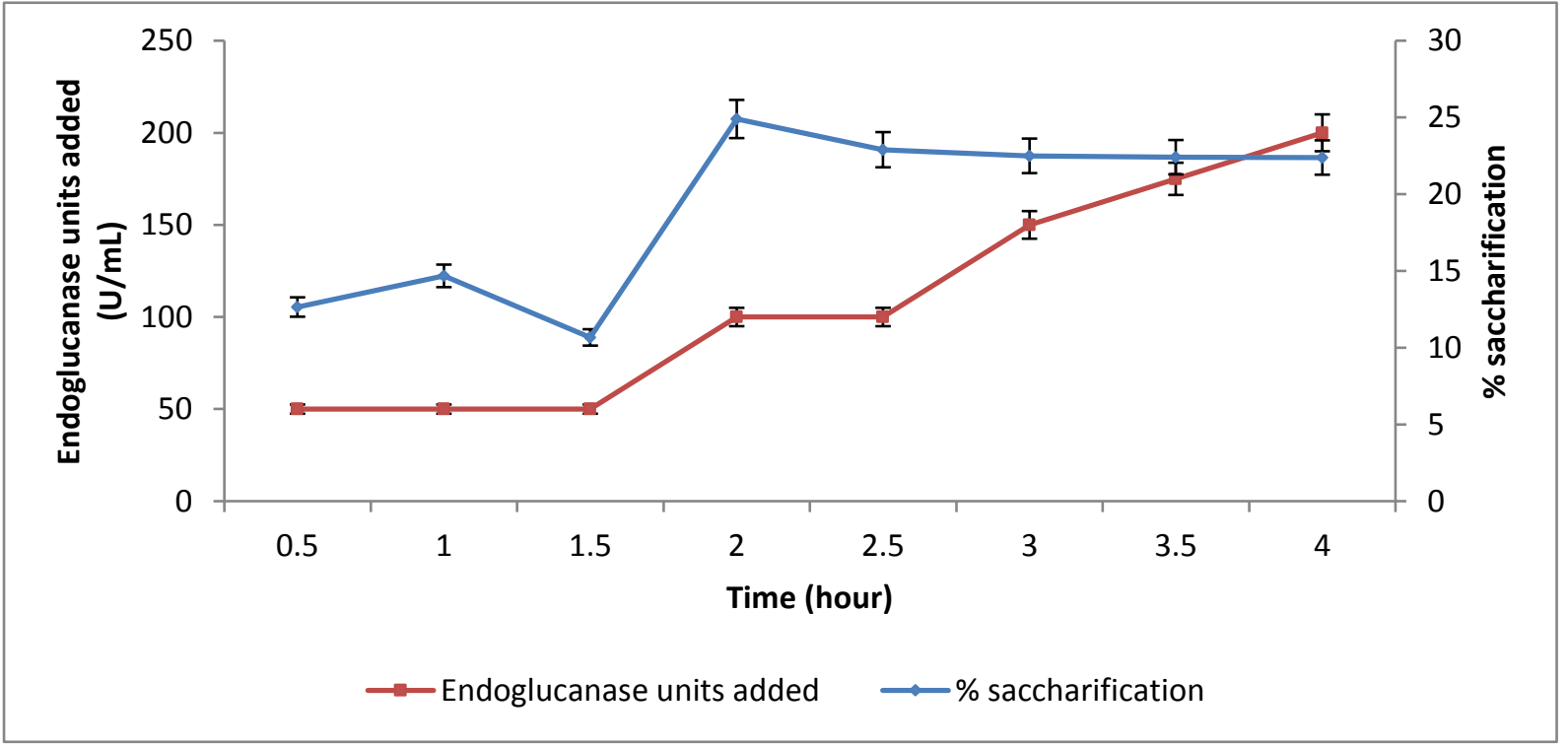

Figure 1. Effect of feedback inhibition on Endoglucanase $\left(\mathrm{N}_{1}\right)$ activity during saccharification of CMC (Carboxy methyl cellulose)

Feedback inhibition of endoglucanase $\mathrm{N}_{1}$ on natural substrate (wheat straw)

Feedback inhibition of endoglucanse $\mathrm{N}_{1}$ was also studied on natural substrate (wheat straw) by the addition of variable enzyme units ranges from $(100-340 \mathrm{U} / \mathrm{mL})$. Initially $100 \mathrm{U} / \mathrm{mL}$ of enzyme were added. After 1.5 hour of incubation, sudden decline in \% saccharification was observed from $14.87 \%$ to $9.8 \%$. Addition of more enzyme units
(120-180 U/mL) did not cause significant increase in \% saccharification. \% saccharification increased from $9.8 \%$ to $18.52 \%$ by the addition of $220 \mathrm{U} / \mathrm{mL}$ of enzyme in the saccharified mixture. After 3 hours of incubation, \% saccharification again began to decrease and addition of more enzyme units ranges $(280-340 \mathrm{U} / \mathrm{mL})$ did not show any increase in \% saccharification values upto 5 hours as shown in (Figure 2). 


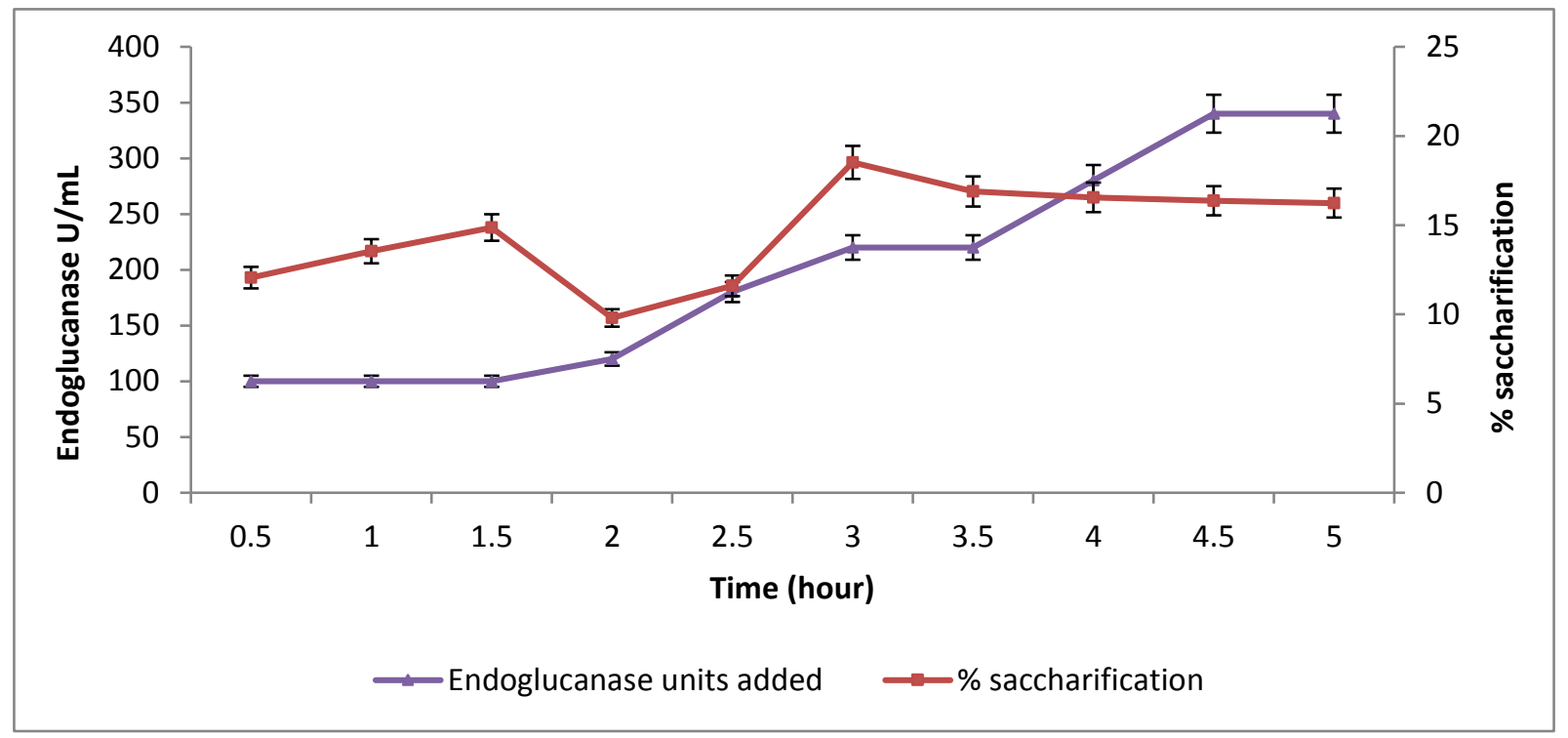

Figure 2. Effect of feedback inhibition on Endoglucanase N1activity during saccharification of wheat straw

Feedback inhibition of exoglucanse $X_{3}$ on synthetic substrate, $p$-itrophenolcellobiose (pNP-C)

Exoglucanse $\mathrm{X}_{3}$ activity loss during saccharification due to feedback inhibition was studied using $p$-nitrophenolcellobiose (pNP-C) as synthetic substrate. Initially 40 $\mathrm{U} / \mathrm{mL}$ of enzyme were added. After 1 hour of incubation, \% saccharification decreased from $28.9 \%$ to $19.5 \%$. Addition of more enzyme units $(60 \mathrm{U} / \mathrm{mL})$, caused a significant increase in \% saccharification from $19.5 \%$ to $30.6 \%$. After 2 hours of incubation, \% saccharification values became level off, inspite of addition of more enzyme units ranges from $(80-100 \mathrm{U} / \mathrm{mL})$ upto 3.5 hours as shown in (Figure 3).

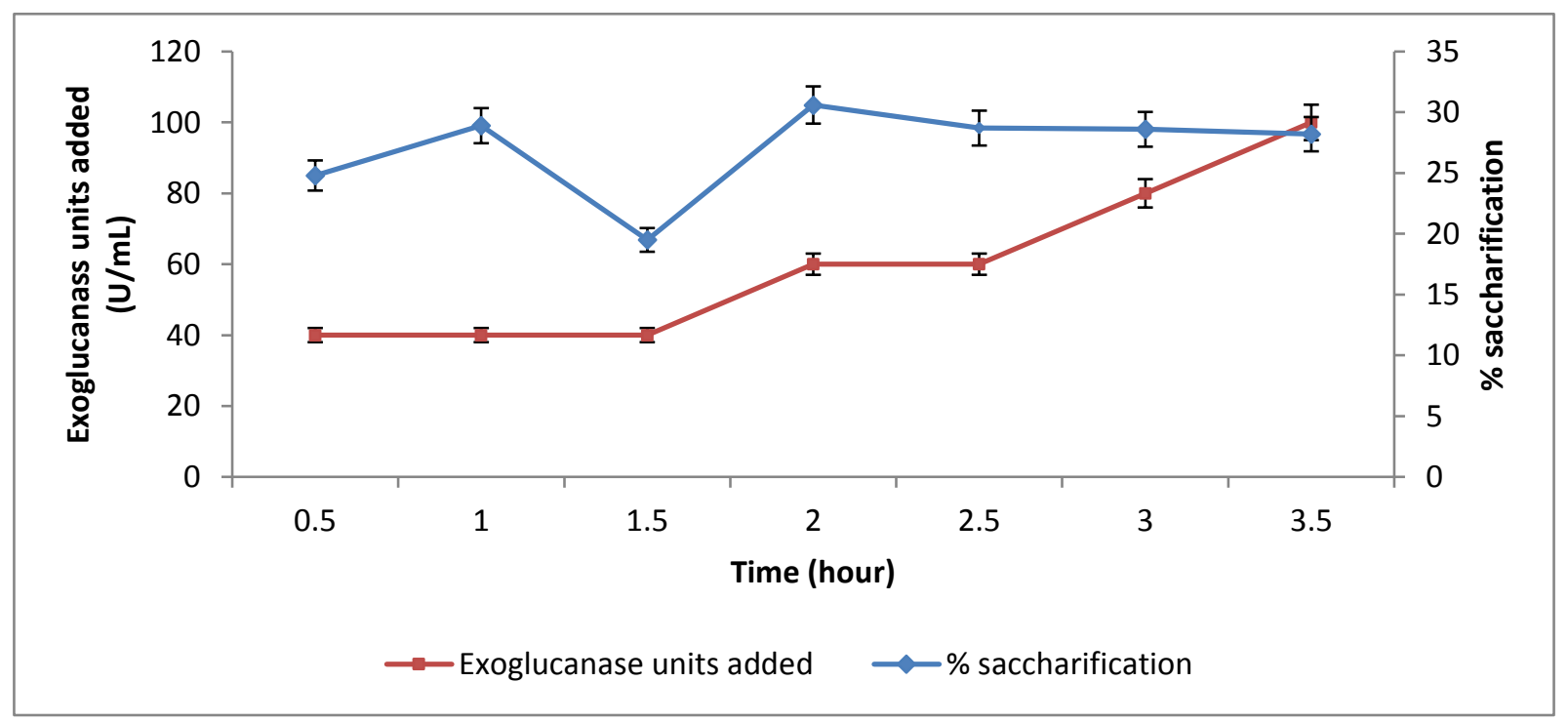


Figure 3. Effect of feedback inhibition of exoglucanse $X_{3}$ on synthetic substrate, $p$ nitrophenolcellobiose ( $p$ NP-C)

Feedback inhibition of exoglucanse $X_{3}$ on natural substrate (wheat straw)

Feedback inhibition of exoglucanase $X_{3}$ was also studied using wheat straw as natural substrate by adding variable units of enzyme ranges from $(80-180 \mathrm{U} / \mathrm{mL})$. Initially addition of $80 \mathrm{U} / \mathrm{mL}$, caused a significant increase in $\%$ saccharification. After 1 hour of incubation, sudden decline in \% saccharification was observed from $20.31 \%$ to $18.34 \%$. Addition of more enzyme units (100 U/mL), caused a little increase in \% saccharification. After this no further increase in \% saccharification was observed inspite of addition of more enzyme units ranges from (120-180 U/mL) upto fourth hour of incubation as shown in (Figure 4).

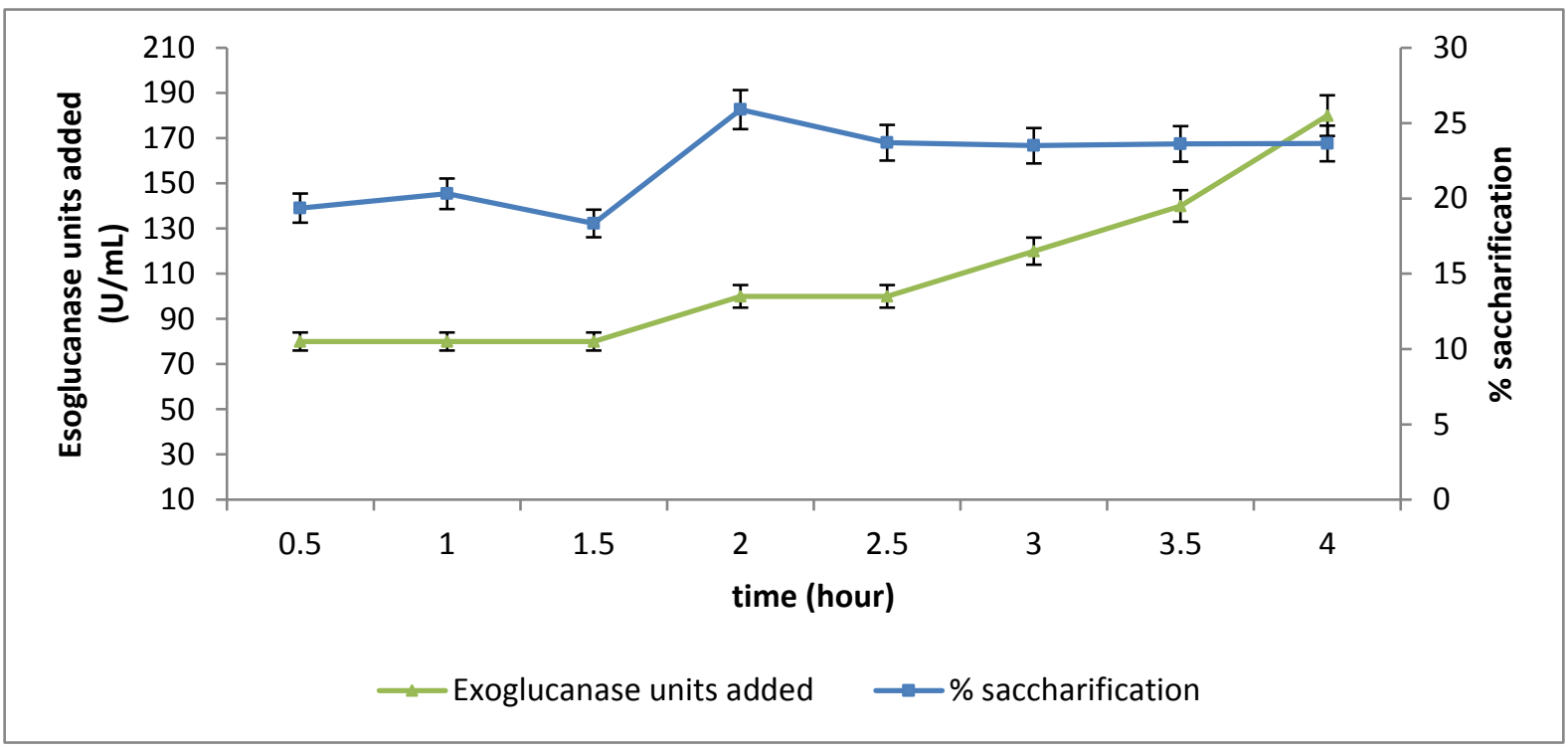

Figure 4. Effect of feedback inhibition of exoglucanse $X_{3}$ on natural substrate during saccharification

Qualitative analysis of end products released by the action of exoglucanse $X_{2}$ Saccharfied sample was analyzed qualitatively by the addition of ceric ammonium nitrate reagent. Cellobiose was detected as the dominant sugar at the temperature of $25^{\circ} \mathrm{C}$ due to the complete disappearance of red colour within 3-5 mins as shown in the (Table 1).

Table 1. Qualitative analysis of cellobiose by CAN (Ceric ammonium nitrate) feedback inhibition of $\beta$-glucosidase $G_{1}$ on synthetic substrate, $p$-nitrophenol-alpha-D glucopyranoside (pNP-G)

\begin{tabular}{|c|c|}
\hline Reducing sugars & Qualitative analysis by (CAN) \\
\hline Cellobiose & +ve \\
\hline Glucose & -ve \\
\hline Arabinose & -ve \\
\hline Sucrose & -ve \\
\hline Maltose & -ve \\
\hline Fructose & -ve \\
\hline
\end{tabular}


Feedback inhibition of $\beta$-glucosidase $\mathbf{G}_{1}$ on synthetic substrate, $p$-nitrophenolalpha-D-glucopyranoside (pNP-G)

In order to observe its feedback inhibition variable units of $\beta$-glucosidase $\mathrm{G}_{1}$ were added on synthetic substrate $p$-nitrophenolalpha-D-glucopyranoside ( $p$ NP-G). Initially, $100 \mathrm{U} / \mathrm{mL}$ of enzyme were added. Successive increase in \% saccharification was observed from $30.60 \%$ to $33.91 \%$ upto 1 hour of incubation. After this, \% saccharification decreased from $33.91 \%$ to $29.40 \%$. Addition of more enzyme unit's ( $150 \mathrm{U} / \mathrm{mL})$, increased $\%$ saccharification from $29.40 \%$ to $34.5 \%$. After this \% saccharification became level off, instead of addition of more enzyme units ranges from (200-240 U/mL) upto 3.5 hours of incubation as shown in (Figure 5).

$\mathrm{Y}$ error bars indicates the standard deviation $( \pm \mathrm{SD})$ among the three replicates which differ significantly at $P<0.05$.

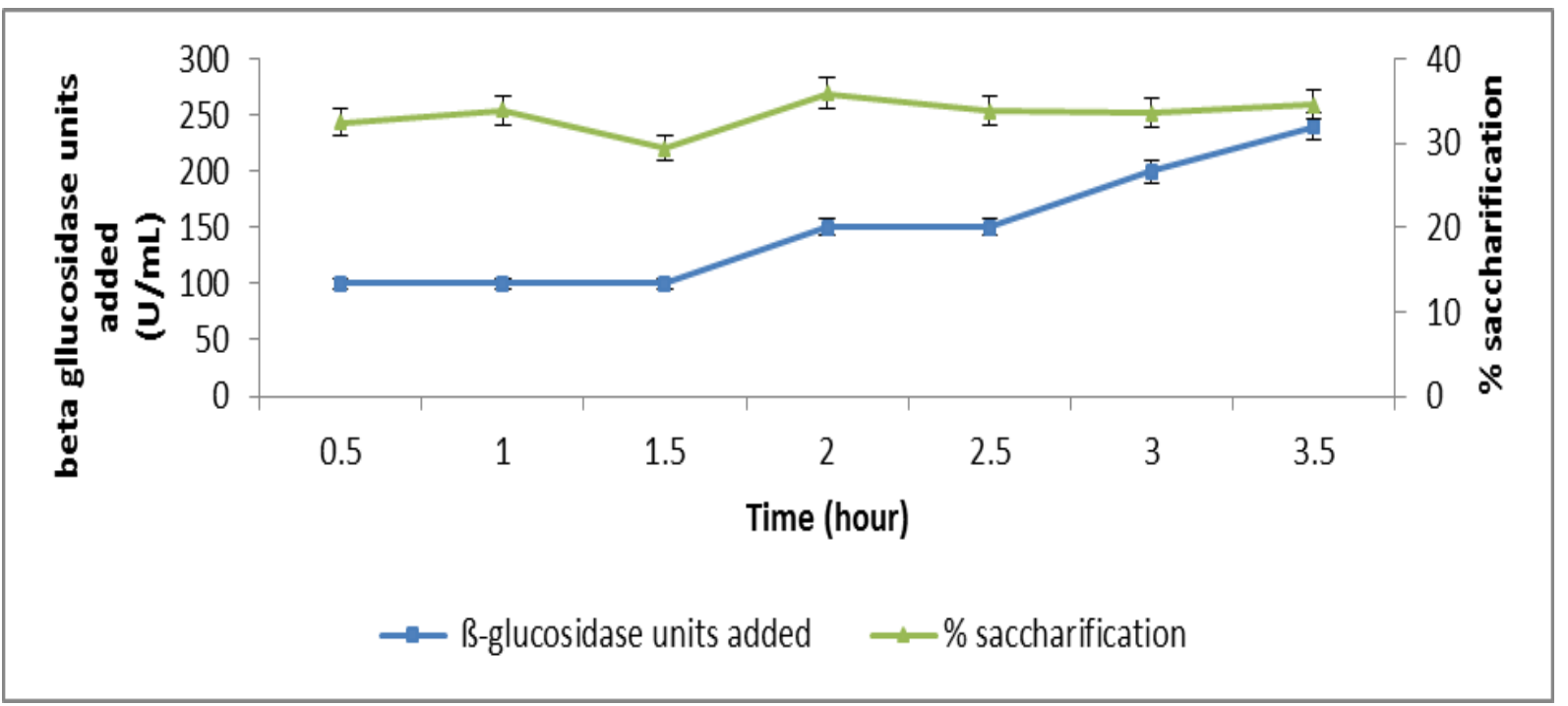

Figure 5. Feedback inhibition of $\beta$-glucosidase $G_{1}$ on synthetic substrate, $p$-nitrophenolalpha-D-glucopyranoside (pNP-G) during saccharification

Feedback inhibition of $\beta$-glucosidase G1on natural substrate (wheat straw)

Feedback inhibition of $\beta$-glucosidase G1 was also observed on natural substrate (wheat straw). Variable units of $\beta$-glucosidase G1 were added with respect to the \% saccharification obtained at different time intervals. Initially $200 \mathrm{U} / \mathrm{mL}$ of enzyme were added. $\%$ saccharification increased upto $29.6 \%$. After this sudden decline in \% saccharification was observed from $29.6 \%$ to $23.6 \%$ after 1 hour of incubation. Addition of more enzyme units $(300 \mathrm{U} / \mathrm{mL})$, caused a significant increase in $\%$ saccharification from $23.6 \%$ to $33.6 \%$ during 2 hours of incubation. After this \% saccharification decreased and no further increase was observed inspite of addition of more enzyme units (300-340 U/mL) upto fourth hours of incubation as shown in (Figure 6). 


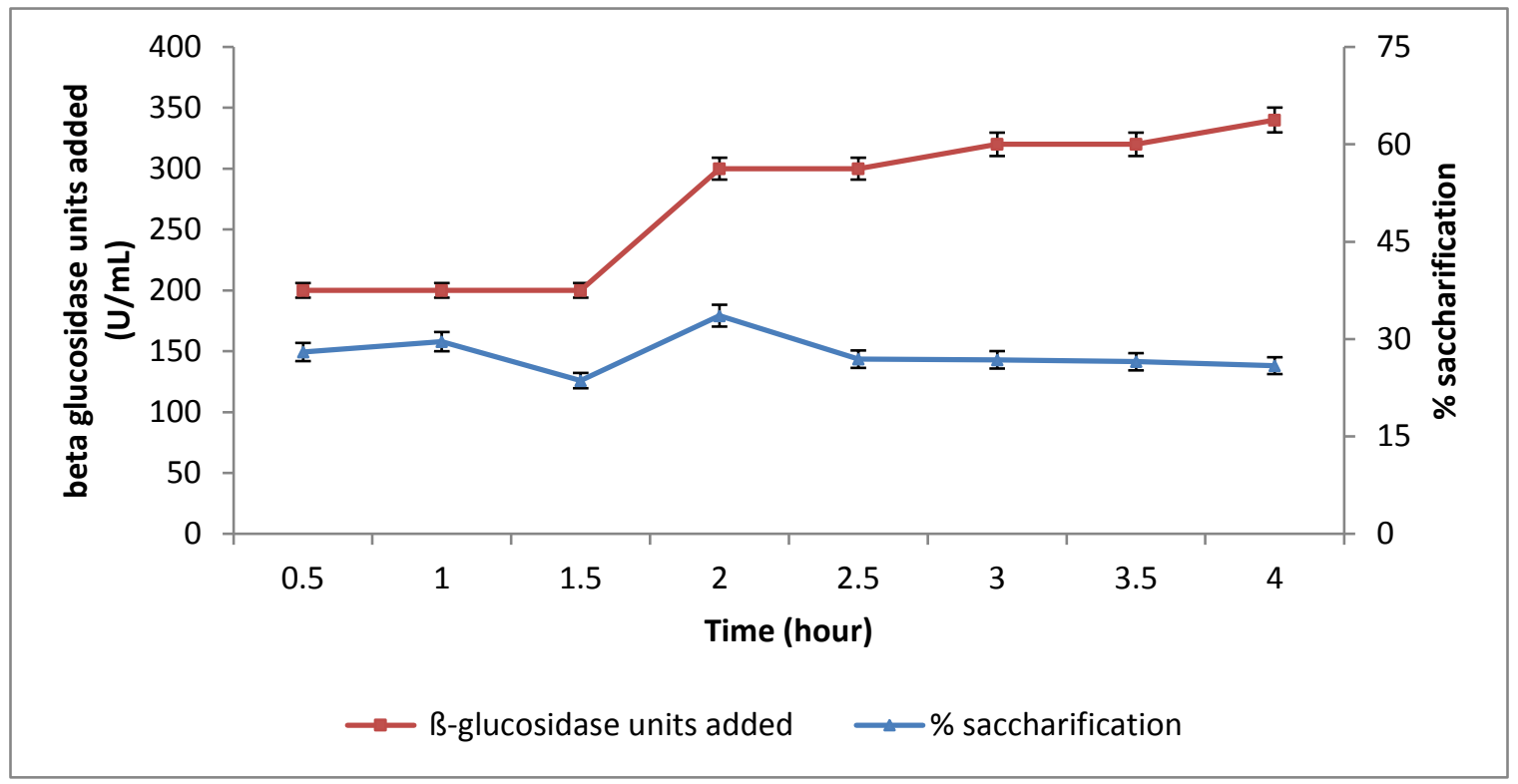

Figure 6. Feedback inhibition of $\beta$-glucosidase G1on natural substrate (wheat straw) during saccharification

Qualitative analysis of end products released by the action of $\boldsymbol{\beta}$-glucosidase $\mathbf{G}_{1}$ Saccharfied sample was analyzed qualitatively by the addition of ceric ammonium nitrate reagent. Glucose was detected as the dominant sugar at the temperature of $25^{\circ} \mathrm{C}$ due to the complete disappearance of red colour within 2-3 mins as shown in the (Table 2).

Table 2. Qualitative analysis of glucose by CAN (Ceric ammonium nitrate)

\begin{tabular}{|c|c|}
\hline Reducing sugars & Qualitative analysis by (CAN) \\
\hline Cellobiose & -ve \\
\hline Glucose & +ve \\
\hline Arabinose & -ve \\
\hline Sucrose & + ve \\
\hline Maltose & -ve \\
\hline Fructose & -ve \\
\hline
\end{tabular}

Optimized saccharification of natural substrate (wheat straw) without feedback inhibition

Present study has revealed continuous increase in $\%$ saccharification under optimized conditions without feedback inhibition of cellulolytic enzymes. Initially, endoglucanase $100 \mathrm{U} / \mathrm{mL}$ were added. After 1 hour, more units ofendoglucanase $\mathrm{N}_{1}$ (220 $\mathrm{U} / \mathrm{mL}$ ) were added in order to protect the activity loss of endoglucanase $\mathrm{N}_{1}$ due to feedback inhibition. Increase in \% saccharification was observed from $14.87 \%$ to $18.52 \%$. After 1.5 hour, $80 \mathrm{U} / \mathrm{mL}$ of exoglucanase $\mathrm{X}_{3}$ were added resulted in increase in \% saccharification from $18.52 \%$ to $20.31 \%$. After 2.5 hours, addition of more exoglucanase $\mathrm{X}_{3}(120 \mathrm{U} / \mathrm{mL})$ were done in order to inhibit the decrease in $\%$ saccharification due to feedback inhibition. Increase in \% saccharification was observed from $20.31 \%$ to $25.9 \%$. After $3^{\text {rd }}$ hour of 
incubation, $200 \mathrm{U} / \mathrm{mL}$ of $\beta$-glucosidase $\mathrm{G}_{1}$ were added. $\%$ saccharification increased from $25.9 \%$ to $29.6 \%$. After fourth hour of incubation, addition of more $\beta$-glucosidase
$\mathrm{G}_{1}$ units $(300 \mathrm{U} / \mathrm{mL})$ increased the $\%$ saccharification from $29.6 \%$ to $33.6 \%$ as shown in (Figure 7).

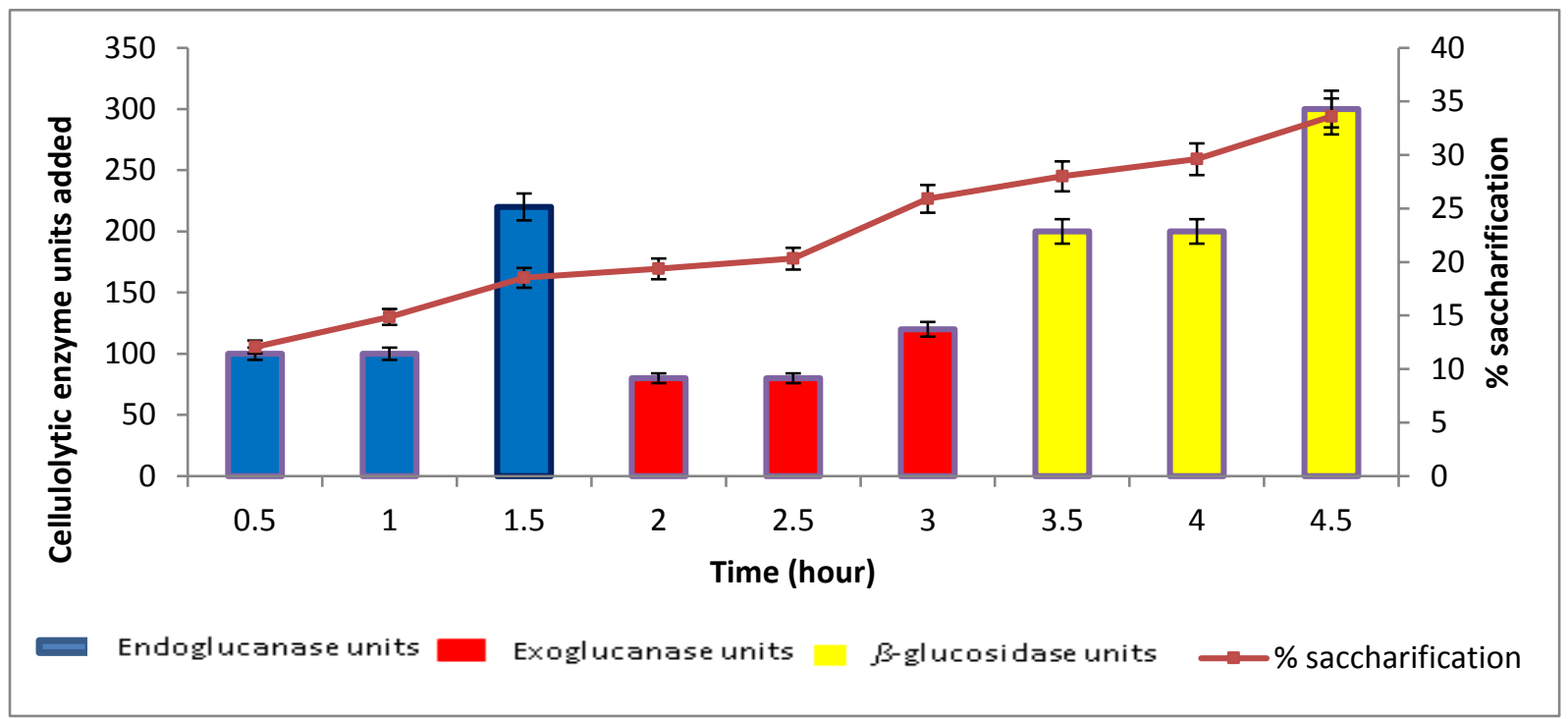

Figure 7. Optimized saccharification conditions without feedback inhibition

High pressure liquid chromatography analysis

HPLC analysis of the saccharified mixture sample was done in order to identify the end products formed under the optimized conditions of saccharification without feedback inhibition of the sequentially added cellulolytic enzymes (Endoglucanase $\mathrm{N}_{1}$, Exoglucanase $\mathrm{X}_{3}$ and $\beta$-glucosidase $\mathrm{G}_{1}$ as shown in (Figure $8 \mathrm{a}, \mathrm{b}$ ).

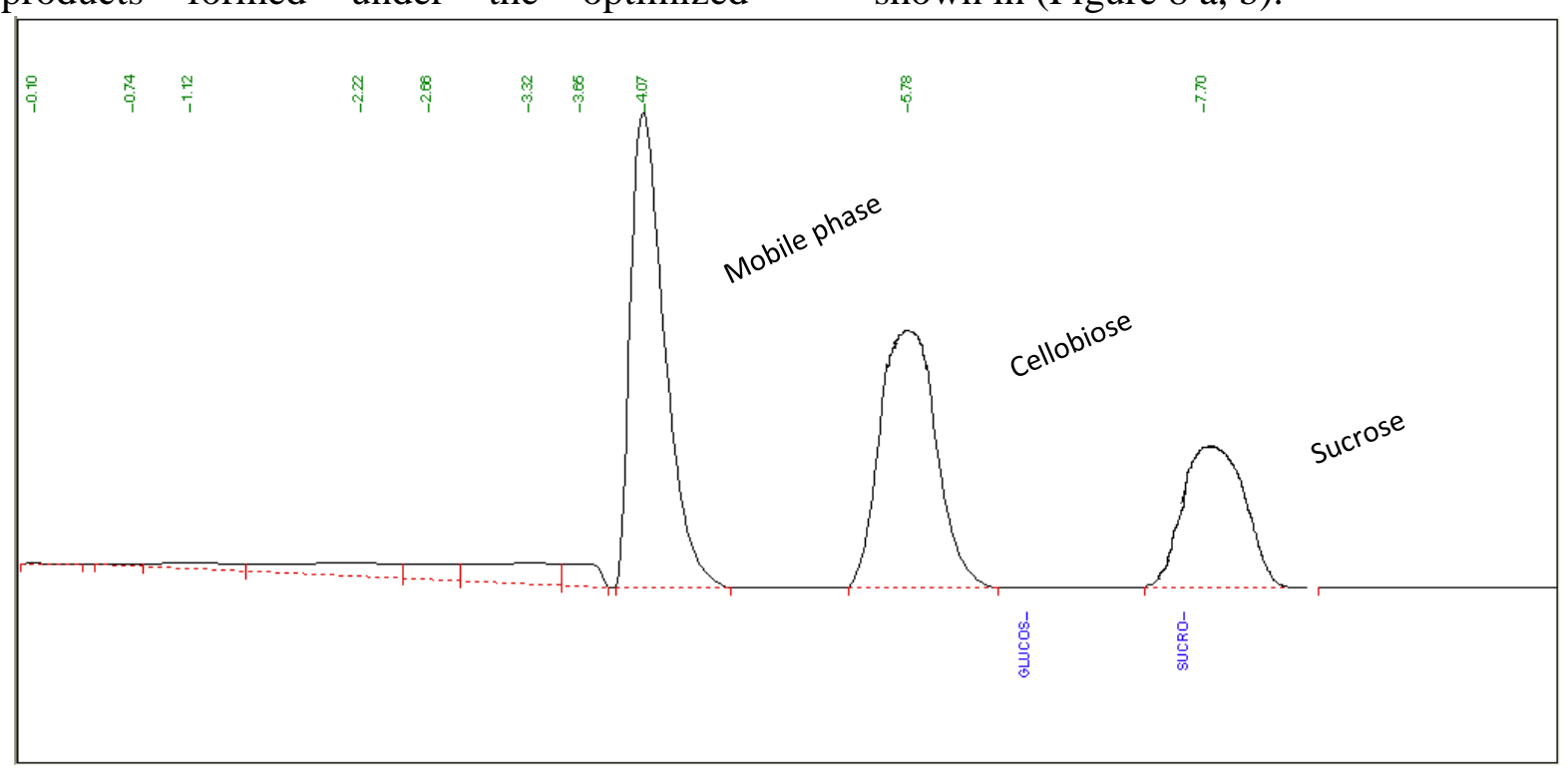

Figure 8a. HPLC chromatogram of the saccharified sample taken after the addition of exoglucanase $X_{3}$ units, showing end product (cellobiose) 


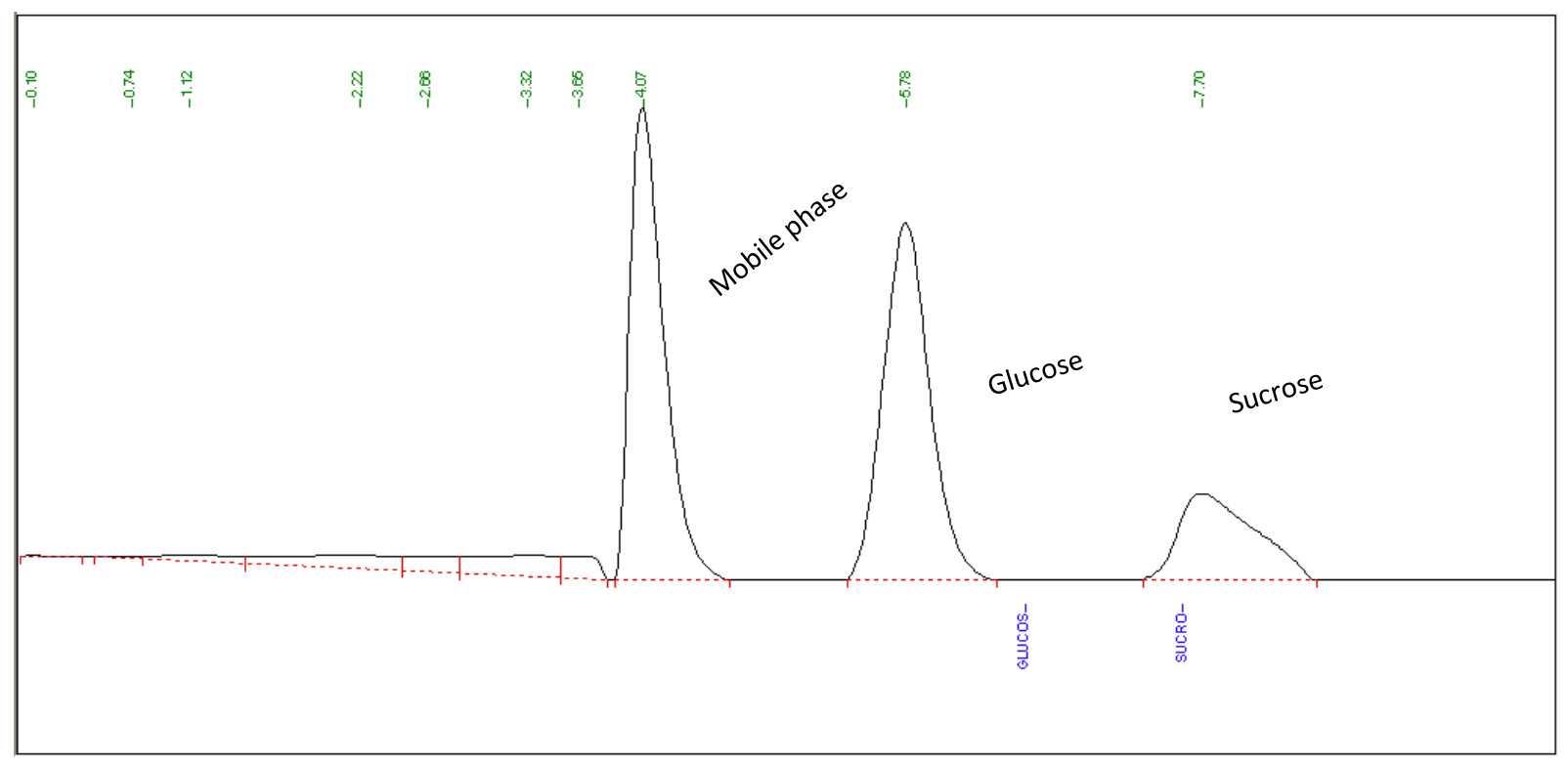

Figure 8b. HPLC chromatogram of the saccharified sample taken after the addition of $\beta$ glucosidase $\mathrm{G}_{1}$ units, showing end product (glucose)

\section{Discussion}

Enzymatic saccharification of wheat straw was carried out by synergistic action of sequentially added cellulolytic enzymes. Initially, percentage saccharification increased gradually due to no inhibitory effect of the little released end products. As the reaction proceeds, sudden decline in percentage saccharification was observed due to feedback inhibition of cellulolytic enzymes.

The result in the present study showed the feedback inhibition of endoglucanase both in case of wheat straw and CMC by decreasing the percentage saccharification from $14.87 \%$ to $9.8 \%$ and $14.68 \%$ to $10.67 \%$ respectively[11].studied the inhibitory effect of end products released during saccharification on the endoglucanase activity obtained from a newly isolated strain of Mucorcircinelloides [12]similarly observed the fluctuations in the rate of percentage saccharification while studying the enzymatic hydrolysis of agro wastes by the addition of endoglucanase $(200 \mathrm{U} / \mathrm{mL})$ isolated from Rhizopusoryzae.
During the study of exoglucanase feedback inhibition was also done on natural (wheat straw) as well as synthetic substrate (pNP-C). Exoglucanase binds with the free ends of the chains generated by the action of endoglucanase in order to produce the cellobiose units. Released end product (cellobiose) inhibited the activity of exoglucanase by occupying the allosteric sites of the free available enzyme. Reversible binding of the non-competitive inhibitor (cellobiose) with the enzyme was overcome by the addition of more enzymatic units. It might be due to the availability of noncompetitive inhibitor (cellobiose) free enzymatic allosteric sites for the rapid release of cellobiose units. Feedback inhibition of exoglucanase in present study during wheat straw and pNP-C saccharification lowered the percentage saccharification from $20.31 \%$ to $18.34 \%$ and $28.9 \%$ to $19.5 \%$ [13], also reported the exoglucanase feedback inhibition using pNP-C as synthetic substrate. [14] reported end product inhibition of exoglucanase Cel7B due to the accumulation of cellobiose by occupying all 
the available sites of the enzyme. Addition of supplemented amount of exoglucanase Cel7B enhanced the yield of enzymatic hydrolysis reaction remarkably.

Loss in activity of $\beta$-glucosidase due to inhibitory effect of end product was studied using natural and synthetic substrates during the present investigation. Glucose was found as a major competitive inhibitor released as final end product of enzymatic hydrolysis process by the action of $\beta$-glucosidase. $\beta$ glucosidases bind to the free cellobiose units and split them into two separate glucose monosaccharides. Glucose as a released end product inhibitor binds to the active or regulatory site of $B$-glucosidase instead of allosteric site due to close similarity in shape with the substrate. This binding rendered the enzyme completely inactive and thus a decrease in percentage saccharification occurred. In present study decrease in percentage saccharification was observed due to feedback inhibition of $B$-glucosidase both in case of wheat straw and pNP-G enzymatic hydrolysis from $29.6 \%$ to $23.6 \%$ and $33.91 \%$ to $29.4 \%$ respectively [15], studied the effect of glucose inhibition on beta-glucosidase activity during enzymatic hydrolysis of softwood. [16] reported the similar comparative analysis of $\beta$ glucosidase inhibition on synthethic and natural substrates.

During the present study released end products of enzymatic hydrolysis reaction were qualitatively analyzed by using CAN (ceric ammonium nitrate) .Oxidation of the organic substrates can be done by using a single electron oxidant i.e. CAN (ceric ammonium nitrate) reagent. At $25^{\circ} \mathrm{C}, \mathrm{CAN}$ did the oxidation of compounds containing hydroxyl group by forming red coloured complex Ce (IV). Reduction of the Ce (IV) complex into $\mathrm{Ce}$ (III) causes the disappearance of red colour. Time taken for the complete reduction of the $\mathrm{Ce}$ (IV) complex depends upon the structure of hydroxyl group containing compounds. Carbohydrates (sugars) however, give an intense red colour that is discharged quickly due to free hydroxyl group associated with the ring structure. The result of present study confirmed the presence of cellobiose and glucose in the saccharified samples due to the complete disappearance of red colour within 3-5 and 2-3 minutes respectively. [17] reported the qualitative analysis of sugars released as end products using CAN.

Optimal of the saccharification conditions reduced the inhibitory effect exerted by released end products on the activity of cellulolytic enzymes. Addition of optimized supplemented amount of enzyme units $(\mathrm{U} / \mathrm{mL})$ during saccharification increases the rate of hydrolysis by lowering the feedback inhibition of cellulolytic enzymes. Availability of inhibitors (end products) free enzymes allosteric sites enhances the conversion of substrate into product. [18] reported the addition of supplemented amount of cellulolytic enzymes in order to inhibit the sudden decline in rate of hydrolysis at different intervals during saccharification. [19] reported the end product inhibition of cellulolytic enzymes while studying the hydrolysis of the lignocellulosic biomass.

High Pressure Liquid Chromatography analysis was done for the separation and identification of the released end products (cellobiose and glucose) from the sample of saccharified mixture. Different sugars solution samples were used as standards. Aminopropyl-bonded phase column interact with the components of injected saccharified sample and separate them on the basis of standard sugar samples retention time. Glucose and cellobiose were identified as major end products released during saccharification under optimized conditions. [20] reported the product inhibition of five Hypocreajecorinacellulases using HPLC (minimum $>98 \%$ purity) and ITC(Isothermal 
titration calorimetry). [21] conducted a study based on the continuous removal of the end products released during saccharification. In this way inhibitory effect on the activity of cellulolytic enzymes might be reduced due to the accumulation of released end products.

Glucose released as end product inhibited the activity of $\beta$-glucosidase is a be a strong inhibitor of the exoglucanase Continuous consumption of glucose before it reaches a specific inhibitory level were found a way for the continuous increase in the trendline of the percentage saccharification. Studies on the inhibitory effect of end products on the activity of cellulolytic enzymes suggested either non-competitive or competitive inhibition. Present investigations showed that reducing sugars released as end product lowered the yield of enzymatic hydrolysis reaction through feedback inhibition.[22] also reported that during cellulose saccharification, cellobiose and glucose released as end products at the end of two heterogeneous reactions lowered the activity of enzymes overall. In the study it was observed that feedback inhibition of cellulolytic enzymes was associated with the accumulation of end products in the saccharified mixture upto specific concentration. [23] studied that rapid consumption of the released end products before it reaches a specific inhibitory concentration is the best solution to get a relieve from feedback inhibition.

During the study, addition of 220 and 100 $\mathrm{U} / \mathrm{mL}$ of endoglucanase in the saccharification mixture of wheat straw and CMC respectively found to overcome the inhibitory effect of released end products on the enzyme's activity. Addition of 100 and 60 $\mathrm{U} / \mathrm{mL}$ of exoglucanase during saccharification of wheat straw and pNP-C also found to lower the effect of feedback inhibition. In case of $\beta$-glucosidase, inhibitory effect of released end product during saccharification of wheat straw and
pNP-G was lowered by the addition of 300 and $150 \mathrm{U} / \mathrm{mL}$ of the enzyme respectively. [23] pointed out the similar findings that the addition of more enzyme units resulted to overcome the feedback inhibition during saccharification. In general overall results in the present study showed that addition of more enzyme units $(\mathrm{U} / \mathrm{mL})$ overcome the feedback inhibition by significantly increasing the rate of enzymatic hydrolysis.

\section{Conclusion}

From the study it was concluded that overall percentage saccharification of natural and synthetic substrate due to feedback inhibition of sequentially added cellulolytic enzymes was found $23.6 \%$ and $29.4 \%$ respectively. Variable concentrations of cellulolytic enzymes were added sequentially in order to overcome the inhibitory effect of the released end products during saccharification. This resulted in a significant increase in percentage saccharification of both natural and synthetic substrate upto $33.6 \%$ and $34.5 \%$ respectively.

\section{Authors' contributions}

Conceived and designed the experiments: $\mathrm{M}$ Razaq \& SA Khan, Performed the experiments: M Razzaq, Analyzed the data: SA Khan, Contributed materials/ analysis/ tools: M Razzaq, SA Khan \& Z Ahmed, Wrote the paper: SA Khan.

\section{References}

1. Brooks AA (2008). Ethanol production potential of local yeast strains isolated from ripe banana peels. Afri J of Biotechnol 7(20): 3749-3752.

2. Rabinovich ML, Melnik MS \& Boloboba AV (2002). Microbial cellulases (Review). Appl Biochem Microbiol 38(4): 305-321.

3. Jonsson LJ, Alriksson B, Nilvebrant NO (2013). Bioconversion of lignocellulose: inhibitors and detoxification. Biotechnol Biofuels 6(1): 16.

4. Koppram, R, Tomas-Pejo E, Xiros C \& Olsson L (2014).Lignocellulosic ethanol production at high-gravity: challenges and perspectives. Trends Biotechnol 32(1): 4653. 
5. Bohlin C, Olsen SN, Morant MD, Patkar S, Borch K \& Westh P (2010). A comparative study of activity and apparent inhibition of fungal $\beta$-glucosidases. Biotechnol Bioengg 107(6): 943-952.

6. McMillan JD, Jennings EW, Mohagheghi A \& Zuccarello M (2012). Comparative performance of pre commercial cellulases hydrolyzing pretreated corn stover. Biotechnol Biofuels 4(1): 29.

7. Singhania R R, Patel AK, Sukumaran RK, Larroche C, Pandey A (2013). Role and significance of beta-glucosidases in the hydrolysis of cellulose for bioethanol production. Bioresour. Technol. 127(1): 500-507.

8. Bertani G (1952). Studies on lysogenesis. I. The mode of phage liberation by lysogenic Escherichia coli. J Bacteriol 62: 293-300.

9. Elliston A, Collins SR, Wilson DR, RobertsI N \& Waldron KW (2013). High concentrations of cellulosic ethanol achieved by fed batch semi simultaneous saccharification and fermentation of wastepaper. Bioresour Technol 134: 117126.

10. Pandita S \& Passey S (2010). Classroom. Resonance. 15(12): 1122-1126.

11. Saha BC (2004). Production, purification and properties of endoglucanase isolated from a newly strain of Mucorcircinelloides. Process Biochem 39(12): 1871-1876.

12. Karmakar M \& Ray RR (2011). Saccharification of agro wastes by the endoglucanase of Rhizopusoryzae. Ann Biol Res 2: 201-208.

13. Gruno $M$, Väljamäe $P$, Pettersson $G$ \& Johansson G (2004). Inhibition of the Trichoderma reeseicellulases by cellobiose is strongly dependent on the nature of the substrate. Biotech Bioeng 86(5): 503-511.

14. Xiao Z, Zhang X, Gregg DJ \& Saddler JN (2004). Effects of sugar inhibition on cellulases and $\beta$-glucosidase during enzymatic hydrolysis of softwood substrates. In Proceedings of the Twenty-
Fifth. Symposium on Biotechnology for Fuels and Chemicals, May, 4-7., Breckenridge, CO. Humana Press. 11151126.

15. Chauve M, Mathis H, Huc D, Casanave D, Monot F \& Ferreira NL (2010). Comparative kinetic analysis of two fungal $\beta$-glucosidases. Biotechnol Biofuels 3(1): 3 .

16. Pandita S \& Passey S (2010). Classroom. Resonance 15(12): 1122-1126.

17. Hodge DB, Karim MN, Schell DJ, McMillan JD (2009). Model-based fedbatch for high-solids enzymatic cellulose hydrolysis. Appl Biochem Biotechnol 152(1): 88-107.

18. Teugjas H \& Valjamae P (2013). Product inhibition of cellulases studied with 14Clabeled cellulose substrates. Biotechnol Biofuels 6(1): 104.

19. Murphy L, Borch K, McFarland KC, Bohlin C \& Westh P (2010). A calorimetric assay for enzymatic saccharification of biomass. Enzyme Microb Techno 146(2): 141-146.

20. Koppram R, Tomas-Pejo E, Xiros C \& Olsson L (2014). Lignocellulosic ethanol production at high-gravity: challenges and perspectives. Trends Biotechno 132(1): 4653.

21. Kadam KL, Rydholm EC \& McMillan JD (2004). Development and validation of a kinetic model for enzymatic saccharification of lignocellulosic biomass. Biotechnol. 20(3): 698-705.

22. Kim JH, Block DE \& Mills DA (2010). Simultaneous consumption of pentose and hexosesugars: an optimal microbial phenotype for efficient fermentation of lignocellulosic biomass. Appl Microbiol Biotechnol 88(5): 1077-1085.

23. McMillan JD, Jennings EW, Mohagheghi A \& Zuccarello M (2012). Comparative performance of pre commercial cellulases hydrolyzing pretreated corn stover. Biotechnol Biofuels 4(1): 29. 